\title{
Novos táxons e novos registros sobre Cerambycidae (Coleoptera) Neotropicais
}

\author{
Maria Helena M. Galileo ${ }^{1,3}$ \& Ubirajara R. Martins ${ }^{2,3}$
}

${ }^{1}$ Museu de Ciências Naturais, Fundação Zoobotânica do Rio Grande do Sul, Caixa Postal 1188, 90001-970 Porto Alegre-RS, Brasil.
galileo@fzb.rs.gov.br
${ }^{2}$ Museu de Zoologia, Universidade de São Paulo, Caixa Postal 42494, 04218-970 São Paulo-SP, Brasil. urmsouza@usp.br
${ }^{3}$ Pesquisador do CNPq.

\begin{abstract}
New taxa and new records on Neotropical Cerambycidae (Coleoptera). New taxa described in Cerambycinae, Eligmodermini: Eligmoderma lara sp. nov. from Venezuela; Elaphidiini: Cratericus gen. nov., type species, C. divaricatus sp. nov., from Jamaica. In Lamiinae, Desmiphorini: Capillicornis gen. nov., type species, C. basilaris sp. nov. from Ecuador; Cotycicuiara acuminata sp. nov. from Panama; C. guiana sp. nov. from French Guiana; Eupromerini: Puanama skillmani sp. nov. from Brazil (Rondônia). New records are presented for Temnopis martinezi Martins, 1995 (Oemini) and Estoloides (E.) aurantius Martins \& Galileo, 2010 (Desmiphorini). The type locality of Hovorelus adiectus Galileo \& Martins, 2010 (Prioninae, Anacolini) is corrected and new data are added.
\end{abstract}

KEYWORDS. Anacolini; Desmiphorini; Elaphidiini; Eligmodermini; Eupromerini; taxonomy.

RESUMO. Novos táxons e novos registros sobre Cerambycidae (Coleoptera) Neotropicais. Novos táxons descritos em Cerambycinae, Eligmodermini: Eligmoderma lara sp. nov. da Venezuela; Elaphidiini: Cratericus gen. nov., espécie-tipo, C. divaricatus sp. nov., da Jamaica. Em Lamiinae, Desmiphorini: Capillicornis gen. nov., espécie-tipo, C. basilaris sp. nov. do Equador; Cotycicuiara acuminata sp. nov. do Panamá; C. guiana sp. nov. da Guiana Francesa; Eupromerini: Puanama skillmani sp. nov. do Brasil (Rondônia). Novos registros são feitos para Temnopis martinezi Martins, 1995 (Oemini) e Estoloides (E.) aurantius Martins \& Galileo, 2010 (Desmiphorini). A localidade-tipo de Hovorelus adiectus Galileo \& Martins, 2010 (Prioninae, Anacolini) é corrigida e novos dados são acrescentados.

PALAVRAS-CHAVE. Anacolini; Desmiphorini; Elaphidiini; Eligmodermini; Eupromerini; taxonomia.

A tribo Eligmodermini (Cerambycinae) foi revista por Martins \& Galileo (2009) e o gênero Eligmoderma Thomson, 1864, então, continha cinco espécies sul-americanas e duas espécies centro-americanas. Acrescentamos mais uma espécie ao gênero.

Os gêneros da tribo Elaphidiini e suas relações filogenéticas foram estudados por Lingafelter (1998). Martins (2005) apresentou uma revisão de todos os táxons presentes na América do Sul. Propomos um gênero novo com base em material da Jamaica.

Em Desmiphorini (Lamiinae), descrevemos um gênero novo monotípico e duas espécies novas em Cotycicuiara Galileo \& Martins, 2008. Este gênero foi revisto por Galileo \& Martins (2008b) e novamente por Martins \& Galileo (2010a), quando uma chave para espécies atualizada foi publicada. Cotycicuiara engloba 11 espécies distribuídas em Trinidad e Tobago, Venezuela, Bolívia e Brasil. Descrevemos mais duas espécies novas.

A tribo Eupromerini foi elegida por Galileo \& Martins (1995) quando os táxons foram revistos e, então, continha quatro gêneros e 17 espécies. Martins \& Galileo (1998) acrescentaram Neopibanga à tribo. Galileo \& Martins (1998) adicionaram uma nova espécie em Puanama Galileo \& Martins, 1995: P. sara Galileo \& Martins, 1998 e Galileo \& Martins (2008a) descreveram duas espécies novas do gênero Iquiracetima: I. ceruri e I. rana. Descrevemos uma espécie nova de Puanama.
O material examinado pertence às seguintes instituições: ACMS, American Coleoptera Museum, San Antonio, Estados Unidos; MZSP, Museu de Zoologia, Universidade de São Paulo, São Paulo, Brasil; USNM, National Museum of Natural History, Washington, D. C., Estados Unidos.

A terminologia dos tubérculos elitrais dos Eupromerini segue Galileo \& Martins (1995): I, tubérculo centro-basal; TC, tubérculo central; TDI, tubérculo dorsal I; TDII, tubérculo dorsal II. Esses dois últimos, situados no terço ou quarto apical dos élitros.

\section{Cerambycinae \\ Eligmodermini \\ Eligmoderma lara sp. nov.}

(Fig. 2)

Etimologia. Nome alusivo à procedência do holótipo.

Fêmea. Cabeça castanho-escura a preta. Fronte fina e densamente pontuada com pelos esparsos amarelados. Tubérculos anteníferos projetados; sulco profundo entre os tubérculos. Vértice com pelos amarelados. Genas com ápice arredondado. Lobos oculares superiores com quatro fileiras de omatídios, tão distantes entre si quanto o dobro da largura de um lobo. Antenas atingem o ápice dos élitros aproximadamente no ápice do antenômero VIII. Escapo castanho-escuro no terço basal e castanho-avermelhado no restante da 
superfície, com pontos próximos no lado interno da metade apical. Antenômeros III-VIII alaranjados na metade basal e castanho-avermelhados na metade apical; IX-XI inteiramente alaranjados.

Protórax castanho-escuro. Pronoto com dois espinhos látero-anteriores desenvolvidos e uma gibosidade centro-posterior pouco projetada; pontuação moderadamente densa; pronoto coberto por pelos amarelados menos sobre os espinhos e na gibosidade. Partes laterais do protórax com duas gibosidades: uma no terço anterior próximo a margem anterior e outra, pouco antes do meio; pontuação e pilosidade semelhantes à do pronoto. Cavidades procoxais fechadas atrás. Prosterno com a metade anterior lisa e brilhante e a metade posterior microesculturada. Mesepisternos e mesepimeros microesculturados com finas rugosidades longitudinais. Metepisternos e metasterno castanho-avermelhados com pelos castanho-avermelhados; centro-longitudinal do metasterno com sulco liso e glabro.

Élitros com os quatro quintos anteriores castanho-amarelados, sem manchas, região basal levemente escurecida; quinto apical e margens elitrais, castanho-escuros. Extremidades elitrais truncadas e desarmadas. Pontuação elitral ocupa toda a superfície. Pelos amarelados, abundantes em todo o élitro.

Fêmures e tíbias com a metade basal alaranjada e a metade apical castanho-escura. Tarsos alaranjados. Urosternitos vermelho-alaranjados com pelos longos.

Dimensões em mm, holótipo fêmea. Comprimento total, 12,9; comprimento do protórax, 2,2; maior largura do protórax, 1,9; comprimento do élitro, 9,4; largura umeral, 3,1.

Material-tipo. Holótipo fêmea, VENEZUELA, Lara: Yacambu Natural Park (13 km SE Sanare, 1560 m), 28-31.VII.1981, J. Heppner col., "cloud Forest" (USNM)

Discussão. Eligmoderma lara $\mathbf{s p . ~ n o v . ~ d i f e r e ~ d e ~ t o d a s ~ a s ~}$ espécies sul-americanas pelos élitros amarelados e pretos, sem faixas claras. As cavidades procoxais das espécies de Eligmodermini são abertas atrás (Martins \& Galileo 2009: 203), mas em E. lara sp. nov. são fechadas.

\section{Elaphidiini Cratericus gen. nov.}

Etimologia. Latim, cratericus $=$ pedra preciosa muito dura. Gênero masculino.

Espécie-tipo. Cratericus divaricatus sp. nov.

Fronte transversal. Sutura frontal visível até entre os lobos oculares superiores. Genas curtas com ápice arredondado. Gula plana. Palpos maxilares apenas mais longos que os labiais. Lobos oculares superiores com seis fileiras de omatídios. Lobos oculares inferiores mais afastados entre si do que a inserção das maxilas. Tubérculos anteníferos apenas projetados. Antenas dos machos com quase o dobro do comprimento do corpo. Escapo robusto, sem sulco no lado dorsal da base, com comprimento igual à metade do comprimento do antenômero III. Antenômeros III a V desarmados, leve- mente intumescidos no ápice, com comprimentos subiguais; antenômeros VI a X intumescidos no lado interno do ápice. Antenômero III não carenado.

Protórax mais largo do que longo. Lados do protórax com tubérculo no nível do terço posterior. Partes laterais do protórax com grande área suboval, central, densamente pontuada. Pronoto com um tubérculo a cada lado da base. Superfície pronotal finamente pubescente. Processo prosternal truncado no ápice; no meio, tão largo quanto um terço de uma mesocoxa. Cavidades procoxais discretamente angulosas no lado externo. Processo mesosternal com superfície articular nos lados, inciso no ápice e aproximadamente tão largo quanto uma mesocoxa. Metepisternos com lados paralelos.

Élitros com pontos crateriformes em toda a superfície. Extremidades elitrais biespinhosas, o espinho externo com o dobro do comprimento do interno.

Fêmures sublineares. Extremidades do meso- e metafêmures com dois espinhos curtos. Metatíbias não carenadas. Metatarsômero I tão longo quanto II+III.

Discussão. Cratericus gen. nov. tem alguns caracteres que o enquadram em Hesperophanini como antenas filiformes e desarmadas, escapo subcilíndrico sem sulco na base, antenômero III sem sulco, cavidades procoxais levemente angulosas no lado externo, processo mesosternal inciso no ápice com superfícies articulares laterais e base das epipleuras sem espículo. Tem também caracteres estranhos a Hesperophanini: lados do protórax com espinho tuberculiforme, pronoto com dois tubérculos látero-basais, processo prosternal truncado, fêmures lineares com espinhos apicais nos meso- e metafêmures.

Cratericus gen. nov. também tem caracteres da tribo Elaphidiini: genas com ápice arredondado, tubérculos anteníferos pouco projetados, protórax mais largo do que longo com tubérculo lateral, pronoto com tubérculos, metepisternos com lados subparalelos e élitros com pubescência em toda extensão. Mas também apresenta caracteres alheios a Elaphidiini: antenômeros basais desarmados e processo prosternal truncado.

Segundo Lingafelter (1998) a monofilia da tribo Elaphidiini é suportada por três sinapomorfias: carenas nas antenas, carena nas tíbias e margem anterior do mesonoto arredondada. Esses caracteres também foram considerados por Lingafelter de pouca utilidade para o reconhecimento da tribo, pois também ocorrem em outras tribos ou podem sofrer reversão dentro dos Elaphidiini. Também elencou outros caracteres que podem facilitar o reconhecimento da tribo, entre os quais antenas com espinhos, com a ressalva que podem estar perdidos. Assim, alguns gêneros de Elaphidiini não apresentam carena nas antenas e nas tíbias nem espinho interno nos antenômeros. Espinhos nas extremidades dos meso- e metafêmures são corriqueiros em Eburiini, mas Cratericus não tem espículo na base das epipleuras nem manchas ebúrneas nos élitros.

Concluímos que Cratericus é de difícil localização em tribo, mas pelo maior conjunto de caracteres comuns com Elaphidiini, julgamos apropriado enquadrá-lo na tribo, embora as antenas sejam desarmadas. 


\section{Cratericus divaricatus sp. nov.} (Fig. 3)

Etimologia. Latim, divaricatus = muito divergente; referente às suas peculiaridades.

Macho. Colorido geral castanho-avermelhado. Cabeça revestida por pubescência esbranquiçada, moderadamente esparsa. Escapo com pontos ásperos $(40 \mathrm{x})$ e densos com pubescência muito esparsa.

Pronoto finamente pubescente com alguns pontos grandes, principalmente, no disco. Élitros pubescentes em toda a extensão com pontos crateriformes contrastantes.

Dimensões, em mm, holótipo macho. Comprimento total, 12,5; comprimento do protórax, 2,3; maior largura do protórax, 3,1; comprimento do élitro, 8,8; largura umeral, 3,3.

Material-tipo. Holótipo macho, JAMAICA, Parish of Clarendon: Claredon Park (2 km S. Rocky Point, near Jackson Bay Cave, $5 \mathrm{~m}$ ), 10.XII.1975, Don \& Mignon Davis col. (USNM).

\section{Lamiinae \\ Desmiphorini \\ Capillicornis gen. nov.}

Etimologia. Latim, capillus $=$ cabelo; cornus $=$ chifre. Alusivo à pilosidade das antenas. Gênero neutro.

Espécie-tipo. Capillicornis basilaris sp. nov.

Fronte transversal. Olhos com granulação média. Lobos oculares superiores com aproximadamente 10 fileiras de omatídios; tão distantes entre si quanto à largura de um lobo. Lobos oculares inferiores com o triplo do comprimento das genas. Antenas (macho) atingem o ápice dos élitros na extremidade do antenômero VIII. Escapo sem cicatriz apical, subcilíndrico, apenas mais curto que o antenômero III. Antenômeros II-VII com franja interna de pelos curtos, mais adensados na extremidade do III e do IV. Antenômero III $(2,0 \mathrm{~mm})$, mais curto que o antenômero IV $(2,7 \mathrm{~mm})$. Antenômeros V-VIII com comprimentos ligeiramente decrescentes. Antenômeros IX-XI quebrados.

Protórax mais largo do que longo; lados com tubérculo arredondado no topo, situado pouco atrás do meio. Pronoto com duas gibosidades látero-anteriores e uma centro-basal menos projetada. Prosterno curto. Processo prosternal, no meio, tão largo quanto um terço de uma procoxa. Cavidades coxais anteriores fechadas atrás e ligeiramente angulosas nos lados. Processo mesosternal tão largo quanto pouco menos da metade de uma mesocoxa; extremidade sem incisão. Cavidades coxais intermediárias abertas.

Élitros com crista centro-basal não encimada por pelos densos. Extremidades elitrais truncadas e com espículo externo. Élitros providos de alguns pelos longos (principalmente quando vistos de perfil).

Fêmures engrossados com pelos eretos e esparsos. Mesotíbias com sulco raso.

Discussão. Capillicornis gen. nov. assemelha-se a Cotycicuiara Galileo \& Martins, 2008, pelos lobos oculares superiores tão distante entre si quanto à largura de um lobo; pelos tubérculos nos lados do protórax arredondados no ápice e próximos do meio e pelas mesotíbias levemente sulcadas. Distingue-se pelos antenômeros basais franjados de pelos curtos e densos; pelo pronoto com gibosidades látero-anteriores e centro-basal; pela presença de pelos e de crista centrobasal nos élitros; pelos fêmures engrossados, com pelos eretos e esparsos. Em Cotycicuiara, os flagelômeros não têm franja de pelos; o pronoto é regularmente convexo; os élitros não têm crista centro-basal nem pelos eretos e os fêmures são pedunculados e clavados, sem pelos eretos.

\section{Capillicornis basilaris sp. nov.}

(Fig. 1)

Etimologia. Latim, basilaris = basal; alusivo à crista centro-basal dos élitros.

Macho. Tegumento corporal castanho-escuro. Base dos fêmures e trocanteres com tegumento avermelhado. Fronte e vértice revestidos por pubescência amarelada, densa; no vértice, pontos pequenos entremeados. Escapo com pubescência amarelada, apenas alguns pontos e pelos amarelados no lado inferior.

Protórax revestido por pubescência amarelada. Pronoto com cinco tubérculos discretos do meio para a base: dois no meio, aproximados entre si, um central e um a cada lado do central, maiores, adiante da constrição basal. Pronoto com pontos pequenos e moderadamente esparsos. Escutelo revestido por densa pubescência amarelada.

Élitros cobertos por pubescência amarelada, ligeiramente esverdeada conforme incidência da luz. Atrás do meio de cada élitro, faixa de pubescência esbranquiçada de contorno bem irregular, oblíqua em sentido descendente da margem para a sutura, bordejada irregularmente de castanho-escuro. A margem anterior da borda castanho-escura com faixa de pubescência amarelo-acobreada, bem visível conforme a incidência da luz. Terço apical dos élitros com mancha lateral, pouco contrastante, de pubescência esbranquiçada.

Fêmures revestidos por pubescência amarelada com pontos contrastantes. Metatarsômero I tão longo quanto o II+III. Face ventral coberta por pubescência amarelada. Lados do metasterno e dos urosternitos I-IV finamente pontuados.

Dimensões em mm, holótipo macho. Comprimento total, 13,6; comprimento do protórax, 2,7; maior largura do protórax, 3,5; comprimento do élitro, 9,7; largura umeral, 4,6.

Material-tipo. Holótipo macho, EQUADOR, Pichincha: Puerto Quito, 1-5.II.1978, J. J. Anderson col. (USNM).

\section{Cotycicuiara acuminata sp. nov.}

$$
\text { (Fig. 4) }
$$

Etimologia. Latim, acuminatus = acuminado; alusivo ao ápice dos élitros.

Macho. Tegumento castanho-avermelhado. Fronte revestida por pubescência amarelo-acastanhada que se estende para 
o vértice onde é mais alaranjada. Vértice liso. Lobos oculares com nove fileiras de omatídios, tão afastados entre si quanto à largura de um lobo. Antenas atingem o ápice elitral na extremidade do antenômero X. Antenômeros revestidos por pubescência amarelo-acastanhada entremeada por pubescência esbranquiçada.

Protórax coberto por pubescência amarelo-acastanhada. Pronoto com pubescência amarelo-acastanhada e com pequenas manchas de pubescência esbranquiçada; alguns pontos no terço basal e liso no restante da superfície. Escutelo com pubescência amarelo-acastanhada.

Élitros com pubescência amarelo-acastanhada e pequenas manchas de pubescência esbranquiçada, irregulares. Pontuação elitral grossa, contrastante, pouco concentrada no dorso da metade anterior e mais esparsa no restante da superfície, região anteapical lisa. Úmeros não projetados. Extremidades elitrais acentuadamente acuminadas.

Face ventral do corpo revestida por pubescência amarelo-acastanhada mesclada por pubescência esbranquiçada. Clava dos fêmures com pubescência amarelo-acastanhada entremeada por pubescência esbranquiçada, esparsa.

Dimensões em mm, machos. Comprimento total, 11,912,7; comprimento do protórax, 2,2-2,3; maior largura do protórax, 3,2-3,4; comprimento do élitro, 8,6-9,3; largura umeral, 4,4-4,5.

Material-tipo. Holótipo macho, PANAMÁ, Panamá: Chepo $(80 \mathrm{~km}$ E), 9-20.V.1971, J. E. Wappes col. (ACMS). Parátipo macho, PANAMÁ, Cocle: El Valle (2400 pés), 16-22.V.1981, J. E. Wappes col. (MZSP).

Discussão. Em Cotycicuiara acuminata sp. nov., a pontuação do pronoto está restrita ao terço basal, a pubescência dos élitros é praticamente uniforme e as extremidades elitrais são acentuadamente acuminadas. Esse conjunto de caracteres é único entre as espécies do gênero. Na chave de identificação das espécies (Martins \& Galileo 2010a), é discriminada com C. multicava Martins \& Galileo, 2010, pelos élitros sem faixas longitudinais de pubescência e pelo pronoto com pontos na base. Cotycicuiara acuminata sp. nov. distingue-se pelos élitros sem faixa larga de pubescência esbranquiçada, pelos ápices elitrais acuminados e pela pontuação do pronoto esparsa e restrita ao terço basal. Em C. multicava, os élitros têm uma faixa larga, transversal, de pubescência esbranquiçada, os ápices elitrais são arredondados e os pontos do pronoto estão restritos a uma fileira na constrição basal.

\section{Cotycicuiara guiana sp. nov.}

(Fig. 5)

Etimologia. Nome específico alusivo ao país de origem.

Fêmea. Tegumento castanho-avermelhado; flagelômeros mais avermelhados. Fronte e vértice cobertos por pubescência esbranquiçada. Lobos oculares superiores com sete fileiras de omatídios, mais próximos entre si do que a largura de um lobo. Antenas atingem o ápice dos élitros no meio do antenômero VIII.
Protórax revestido por pubescência predominantemente amarelo-acastanhada; intercalada por alguns pelos brancos nos lados e na região basal. Pronoto com duas gibosidades ânterolaterais muito discretas. Pontos do pronoto bem distantes entre si, exceto nas gibosidades; constrição basal, com pontos lado a lado. Escutelo com pubescência amarelada, esparsa.

Élitros com o sexto basal revestido por pubescência amarelo-acastanhada que se prolonga estreitamente, junto à sutura; do sexto anterior ao meio, com pubescência esbranquiçada entremeada por pontos glabros e brilhantes; quarto e quinto sexto com pubescência acastanhada, intercalada por faixa irregular de pubescência branca com ramificações anterior e posteriormente e, no dorso próximo a sutura, em forma de "Y"; sexto apical coberto por pubescência branca. Úmeros discretamente projetados. Extremidades elitrais arredondadas.

Face ventral coberta por pubescência esbranquiçada. Mancha preta no lado externo da clava dos meso- e metafêmures.

Dimensões em mm, holótipo fêmea. Comprimento total, 8,6; comprimento do protórax, 1,8; maior largura do protórax, 2,5; comprimento do élitro, 6,2; largura umeral, 3,4.

Material-tipo. Holótipo fêmea, GUIANA FRANCESA, estrada de Kaw (km 18), 26.VIII.1995, J. E. Wappes col. (ACMS).

Discussão. Cotycicuiara guiana sp. nov. tem padrão de colorido dos élitros sem faixas longitudinais de pubescência esbranquiçada e a base é revestida por pubescência acastanhada; o pronoto é pontuado. Estas características conduzem ao item 9 da chave de identificação das espécies (Martins \& Galileo 2010a), junto com A. pertusa Martins \& Galileo, 2010. Distingue-se pela faixa de pubescência esbranquiçada larga, com pontos grossos e contrastantes; pela metade apical dos élitros acastanhado com faixa irregular de pubescência esbranquiçada com estreitas ramificações, no dorso em forma de "Y"; sexto apical coberto por pubescência branca. Em C. pertusa, a faixa de pubescência esbranquiçada anterior dos élitros é mais estreita, bordas irregulares, intercalada por pontos menores. A faixa de pubescência acastanhada atrás do meio é mais estreita e uniforme, sem faixas de pubescência esbranquiçada e todo o terço apical é coberto por pubescência esbranquiçada.

$\mathrm{O}$ aspecto da faixa elitral larga de pubescência esbranquiçada entremeada por pontos grandes em C. guiana sp. nov. é semelhante ao de $C$. multicava. Difere pelo pronoto pontuado em toda a superfície, pelos élitros com a faixa larga de pubescência esbranquiçada que não toca a sutura e pelos meso- e metafêmures com clava mais robusta e escurecida no lado externo. Em C. multicava, o pronoto é liso com pontos restritos a contrição basal; a faixa larga de pubescência esbranquiçada dos élitros estende-se até a sutura e a clava dos meso- e metafêmures é menos pronunciada.

\section{Eupromerini Puanama skillmani sp. nov.} (Fig. 6)

Etimologia. Nome específico é uma homenagem a F. W. Skillman Jr, coletor do holótipo. 
Macho. Tegumento castanho-avermelhado. Cabeça revestida por pelos escamiformes, esbranquiçados; pontuação densa, pontos contrastantes e entremeados na pubescência. Lo- bos oculares superiores com cinco fileiras de omatídios ligados aos lobos inferiores por única fileira de omatídios. Antenas com onze artículos. Escapo subpiriforme, com
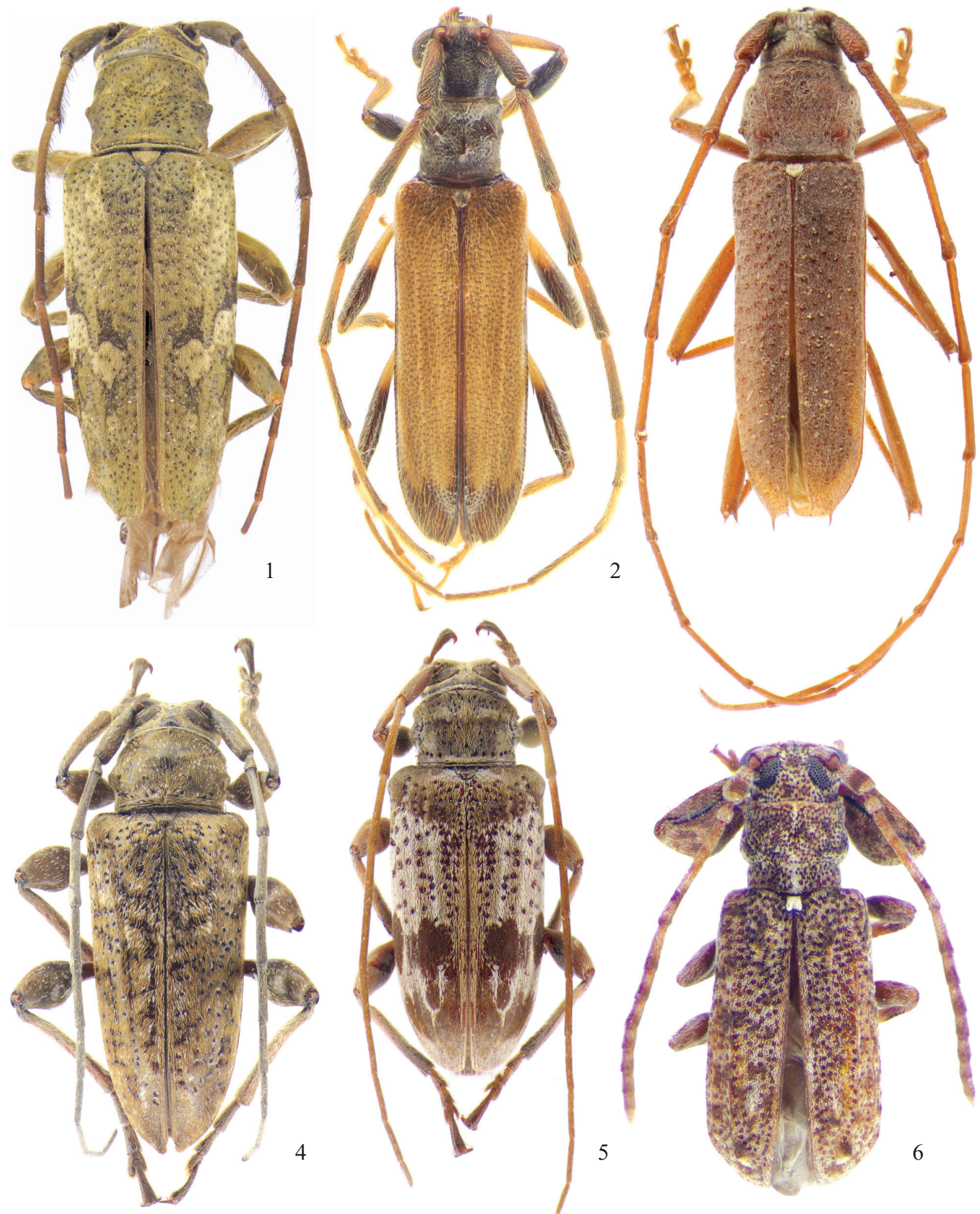

Figs. 1-6. 1. Capillicornis basilaris sp. nov., holótipo macho, comprimento, 13,6 mm; 2. Eligmoderma lara sp. nov., holótipo fêmea, comprimento, 12,9 $\mathrm{mm}$; 3. Cratericus divaricatus sp. nov., holótipo macho, comprimento, $12,5 \mathrm{~mm} ; 4$. Cotycicuiara acuminata sp. nov., holótipo macho, comprimento, 12,5 mm; 5. Cotycicuiara guiana sp. nov., holótipo fêmea, comprimento, $8,6 \mathrm{~mm} ; 6$. Puanama skillmani sp. nov., holótipo macho, comprimento, $3,8 \mathrm{~mm}$. 
pubescência escamiforme, esbranquiçada; tegumento castanho-amarelado com anel central castanho-avermelhado. Antenômero III castanho-amarelado com dois anéis escuros, um pouco antes do meio e outro no quarto apical. Antenômeros IV-X castanho-amarelados, escurecidos no ápice; comprimentos gradualmente decrescentes.

Protórax mais largo do que longo com a constrição basal muito pronunciada. Pronoto com superfície revestida por pubescência esbranquiçada, escamiforme, esparsa, entre os pontos; faixa centro-longitudinal, irregular, de pubescência esbranquiçada densa. Escutelo densamente coberto por pubescência escamiforme, esbranquiçada.

Élitros revestidos por pubescência escamiforme, esbranquiçada, intercalada por pontos. Em cada élitro, região centro-basal com crista alongada (I); quarto apical com dois tubérculos encimados por tufos de pelos: um dorsal próximo da sutura (TDI), outro mais posterior e mais distante da sutura (TDII); carena centro-longitudinal (TC) da crista centro-basal (I) até o tufo de pelos mais posterior (TDII).

Profêmures revestidos, na face dorsal, por pubescência escamiforme, esbranquiçada e esparsa; região ventral com grande área basal lisa e brilhante. Meso- e metafêmures com pedúnculo amarelado. Tíbias com anel escuro no terço basal. Face inferior do corpo até o primeiro urosternito, pontuados.

Dimensões em mm, holótipo macho. Comprimento total, 3,8 ; comprimento do protórax, 0,8 ; maior largura do protórax, 1,5; comprimento do élitro, 2,7; largura umeral, 1,8.

Material-tipo. Holótipo macho, BRASIL, Rondônia: Ariquemes (3 km N, Linha C/20 of B-65 “Ahreinholz trail”, 10'37”S 2'48”W), 20.III.1991, F. W. Skillman Jr. col. (MZSP, doação de F. W. Skillman Jr).

Discussão. Em Puanama skillmani sp. nov., as antenas têm onze artículos como em P. sinopia Galileo \& Martins, 1995. Em P. sara Galileo \& Martins, 1998 e P. caraca Galileo \& Martins, 1995 as antenas têm 10 artículos. Difere de $P$. sinopia pelos lados do protórax com gibosidade mais pronunciada, pelos tubérculos do quarto apical dos élitros: TDI a frente do TDII; pelos élitros inteiramente revestidos por pubescência esbranquiçada, intercalada pelos pontos grossos equidistantes. Em P. sinopia, os tubérculos do quarto apical dos élitros são subparalelos, TDI pouco abaixo do TDII, a pubescência elitral é esparsa, com mancha de pubescência mais concentrada, irregular, nos lados dos élitros, pouco acima do meio.

\section{Novos registros, adendas e correções}

\section{Cerambycinae, Oemini, Oemina}

Temnopis martinezi Martins, 1985

Temnopis martinezi Martins, 1985: 170; 1997: 89; Monné, 2005: 437 (cat.).

A espécie foi originalmente descrita da Argentina com registros em San Luís, Salta, Chaco). Estende-se a distribuição para a Bolívia.

Material examinado. BOLÍVIA, Santa Cruz: Cordillera (Camiri, 20²’S 6332'W, 830 m), fêmea, 6-8.XI.2007, S. W. Lingafelter col., MV/UV light (ACMS).

\section{Lamiinae, Desmiphorini}

Estoloides (E.) aurantius Martins \& Galileo, 2010

Estoloides (E.) aurantius Martins \& Galileo, 2010b: 87, fig. 5.

A espécie foi originalmente descrita do México, Quintana Roo: Bacalar. Acrescentamos novas ocorrências.

Material-examinado. MÉXICO, Quintana Roo: San Felipe (18-24 km N, carretera, ponte), macho, 27.V.-1.VI.1984, J. E. Wappes col. (ACMS). GUATEMALA, Zacapa: San Lorenzo (12-14 km S, 1000-2000 pés), macho, 3-6.VI.1999, J. E. Wappes col. (MZSP).

\section{Prioninae, Anacolini}

Hovorelus adiectus Galileo \& Martins, 2010

Hovorelus adiectus Galileo \& Martins, 2010: 35.

Alertados pelo coletor do holótipo que forneceu dados mais precisos sobre o local de coleta (Galileo \& Martins 2010), apresentamos correções e adendas.

Localidade-tipo. Holótipo macho, COSTA RICA, Heredia: (Estación El Ceibo, 10 km SE La Virgen, 450-550 m, 10²0’N, 8405’W), 7-14.IV.2003, E. G. Riley col. (ACMS).

\section{AGRADECIMENTOS}

A James E. Wappes (ACMS) e Steven W. Lingafelter (USNM) pelo empréstimo de material para estudo; ao Edward G. Riley (Texas A\&M University) pelas informações sobre localidade-tipo; a Eleandro Moysés (Bolsista PIBIC/CNPQ/FZB-RS) pelas fotografias e tratamento digital das imagens.

\section{REFERÊNCIAS}

Galileo, M. H. M. \& U. R. Martins. 1995. Revisão da tribo Eupromerini, trib. n. (Coleoptera, Cerambycidae) da região neotropical. Revista Brasileira de Entomologia 39: 131-150.

Galileo, M. H. M. \& U. R. Martins. 1998. Notas e descrições em Lamiinae (Coleoptera, Cerambycidae) com garras tarsais apendiculadas ou bífidas e revisão do $1^{\circ}$ grupo de espécies do gênero Malacoscylus Thomson, 1868. Revista Brasileira de Entomologia 41: 249-256.

Galileo, M. H. M. \& U. R. Martins. 2008a. Novos táxons de Lamiinae Neotropicais (Coleoptera, Cerambycidae, Lamiinae). Les Cahiers Magellanes 73: 1-9.

Galileo, M. H. M. \& U. R. Martins. 2008b. Novo gênero de Desmiphorini com cinco espécies novas (Coleoptera, Cerambycidae, Lamiinae). Les Cahiers Magellanes 83: 1-10.

Galileo, M. H. M. \& U. R. Martins. 2010. Novas espécies de Prioninae e de Cerambycinae (Cerambycidae) da Região Neotropical. Revista Brasileira de Entomologia 54: 32-37.

Lingafelter, S. W. 1998. The genera of Elaphidiini Thomson 1864 (Coleoptera: Cerambycidae). Memoirs of the Entomological Society of Washington 20: $1-118$

Martins, U. R. 1985. Novos táxons, sinonímias, notas e nova combinação em Cerambycidae (Coleoptera) neotropicais. Revista Brasileira de Entomologia 29: 169-180.

Martins, U. R.1997. Tribo Oemini, p. 5-155. In: Martins, U. R. (org.). Cerambycidae sul-americanos. v. 1, 217 p.

Martins, U. R. 2005. Tribo Elaphidionini, p. 1-394. In: Martins, U. R. (org.). Cerambycidae sul-americanos. v. 7, ii +394 p. 
Martins, U. R. \& M. H. M. Galileo. 1998. Novas sinonímias e novos táxons em Cerambycidae (Coleoptera) neotropicais. Revista Brasileira de Zoologia 15: 47-58.

Martins, U. R. \& M. H. M. Galileo. 2009. Tribo Eligmodermini, p. 201221. In: Martins, U. R. (org.). Cerambycidae sul-americanos. v. 10, $\mathrm{vi}+373 \mathrm{p}$.

Martins, U. R. \& M. H. M. Galileo. 2010a. New species of the genus
Cotycicuiara Galileo and Martins, 2008 (Cerambycidae, Lamiinae, Desmiphorini). Insecta Mundi 134: 1-6.

Martins, U. R. \& M. H. M. Galileo. 2010b. Novas espécies, nova sinonímia e novo registro em Cerambycidae (Coleoptera) do México e da América do Sul. Papéis Avulsos de Zoologia 50: 83-90.

Monné, M. A. 2005. Catalogue of the Cerambycidae (Coleoptera) of the Neotropical region. Part I. Subfamily Cerambycinae. Zootaxa 946: 1-765.

Received 2/12/2011; accepted 28/6/2012

Editor: Marcela Laura Monné 